\title{
Exophytic Polypoid Lesion
}

National Cancer Institute

\section{Source}

National Cancer Institute. Exophytic Polypoid Lesion. NCI Thesaurus. Code C40560.

A raised, outward growing lesion from the surface epithelium or the lumen of an organ.

Representative examples include adenomatous and fibroepithelial polyps. 